\title{
ETNOMATEMÁTICA: UMA EXPERIÊNCIA NA CASA FAMILIAR RURAL DE BREVES/PA
}

\section{ETHNOMATHEMATICS: AN EXPERIENCE IN THE RURAL FAMILY HOME IN BREVES/PA}

\author{
Odilson de Paiva OLIVEIRA (UFPA) \\ Alan Gonçalves LACERDA (UFPA) ${ }^{2}(9)$ \\ Robson dos santos FERREIRA(UFPA) ${ }^{3}$
}

\begin{abstract}
Resumo: Objetivamos analisar quais contribuições podem ser observadas no processo de ensino de matemática a partir do desenvolvimento de atividades na perspectiva da Etnomatemática na Escola Comunitária Casa Familiar Rural do Município de Breves/PA. Utilizou-se a perspectiva de Etnomatemática de D'Ambrosio, que a apresenta como meio para o reconhecimento da influência das culturas no modo de lidar com situações e problemas do cotidiano. Os sujeitos participantes foram: os alunos da turma EJA (Educação de Jovens e Adultos) quarta etapa; a turma do $3^{\circ}$ ano do ensino médio; o técnico em Floresta da CFR. As reflexões realizadas nos fazem inferir que um trabalho articulado entre os conhecimentos culturais locais, atrelados com os conhecimentos matemáticos escolares e viabilizados pelo trabalho na perspectiva da Etnomatemática propicia um ambiente favorável para a formação de alunos reflexivos, capazes de articular os diversos saberes (escolares e não escolares) em prol de sua formação cidadã.
\end{abstract}

\begin{tabular}{lr} 
Palavras-chave: & \multicolumn{2}{c}{ Etnomatemática. } \\
Conhecimentos & Matemáticos. $\quad$ Educação
\end{tabular} Matemática.

\begin{abstract}
We aim to analyze which contributions can be observed in the process of teaching mathematics from the development of activities from the perspective of Ethnomathematics at the Rural Family House Community School in the city of Breves/PA. We used D'Ambrosio's Ethnomathematics perspective, which presents it as a means of recognizing the influence of cultures in the way of dealing with everyday situations and problems. The participating subjects were students from the EJA (Youth and Adult Education) fourth stage; the 3rd year high school class; the Forestry Technician at CFR. The reflections made lead us to infer that a work articulated between local cultural knowledge, linked to school mathematical knowledge and made possible by work from the perspective of Ethnomathematics provides a favorable environment for the formation of reflective students, capable of articulating the various knowledge (school and non-school students) in favor of their citizenship education.
\end{abstract}

Keywords: Ethnomathematics. Mathematical Knowledge. Mathematic education.

\section{INTRODUÇÃO}

\footnotetext{
${ }^{1}$ Possui graduação em Licenciatura Plena em Matemática pela Universidade Federal do Pará (2014). Atuou como Professor Colaborador da Universidade Federal do Pará, sendo Professor pedagógico - concursado - Secretaria Municipal de Educação de Breves. E-mail: odilsonpaiva@hotmail.com

${ }^{2}$ Doutor em Educação em Ciências e Matemática pela Universidade Federal do Mato Grosso É Professor Adjunto e coordenador do curso de matemática do Campus Universitário do Marajó-Breves. Líder do Grupo de Estudos de Práticas de Linguagem e Comunicação no Ensino e Aprendizagem em Matemática. Fez parte do Grupo de estudos em Linguagem Matemática/UFPA UFMT (2017).E-mail: alanlacerda@ufpa.br

${ }^{3}$ Doutor em Educação Matemática, experiência docente na Educação Básica e superior e como Gestor Educacional. Atualmente professor da Universidade Federal do Pará, trabalhando com os processos de Ensino e de Aprendizagem de Matemática e suas Tecnologias. E-mail: robsonf@ufpa.br
} 
A Etnomatemática, considerada por D’Ambrósio como à arte ou técnica de compreender as matemáticas em suas diversas manifestações socioculturais, teve início na década de 70 e à qual D’Ambrósio se reporta como um programa de pesquisa. Trata-se de uma abordagem com visão holística e transdisciplinar de olhar a matemática, não enrijecida e disciplinar em seu tratamento. O ensino da matemática, na perspectiva da Etnomatemática, contempla o enfoque sociocultural, e decorre daí um enriquecimento para a ação pedagógica do professor.

O trabalho na perspectiva da Etnomatemática vem sendo considerado revolucionário na formação profissional, pois ultrapassa um enfoque tradicional, atingindo as mais variadas regiões de inquéritos (KNIJNIK, 2007; D’AMBROSIO, 2018). Tais avanços levam-nos a considerar também a Educação como um processo democrático o que também se pode pensar na acepção de D'Ambrósio de que essa linha de estudos é embebida na ética. $\mathrm{O}$ autor reitera sobre a Etnomatemática "que privilegia o raciocínio qualitativo e está ligada sempre a uma questão de transversalidade de natureza ambiental, política e social, sem estar desvinculada de outras manifestações culturais, tais como a artística e a religiosa" (D’AMBROSIO, 2011, p. 44-45).

D'Ambrósio (2018, p. 1) ainda atribui a ideia de que a "Etnomatemática, que surge do reconhecimento de que diferentes culturas têm maneiras diferentes de lidar com situações e problemas do cotidiano e de dar explicações sobre fatos e fenômenos naturais e sociais".

Em estudos de Knijnik \& Duarte (2010), ao problematizar o que expressavam os discursos sobre a importância de trazer a "realidade" do aluno para as aulas de matemática, pontuou que esse movimento não se restringe aos trabalhos com enfoque sobre Etnomatemática.

Diante desse panorama, questionamo-nos: Quais contribuições e contributos podem ser observados no processo de ensino de matemática, a partir do desenvolvimento de atividades, na perspectiva da Etnomatemática, na Escola Comunitária, Casa Familiar Rural, do Município de Breves/PA?

Ao apontar essas relações, pretende-se aqui não apenas se reportar a trazer a "realidade" do aluno para as aulas de matemática, mas, sobretudo, configura o comportamento humano essencial ao qual D’Ambrósio (2018) denomina por ética da diversidade:

- Respeito pelo outro, com todas as diferenças;

- Solidariedade com o outro na satisfação de todas as suas necessidades;

- Colaboração com o outro na preservação do suporte comum para a vida.

Para tanto, os resultados da pesquisa aqui arrolados se deram a partir de uma vivência em uma Escola Comunitária Casa Familiar Rural de Breves (ECCFRB). Trata-se de uma escola localizada no 
Rio Mapuá, distrito de São Miguel dos Macacos, em Breves-ilha de Marajó.

Desenvolver a investigação consiste em uma tentativa de articular uma perspectiva crítica à Etnomatemática, que pode ser mais ampla a partir de uma subordinação de valores e crenças.

$\mathrm{Na}$ investigação aqui proposta, desdobrar-se-á, nos tópicos seguintes, algumas perspectivas apresentadas à Etnomatemática, no intuito de compreender os seus mais diferentes olhares e manifestações.

\section{A ETNOMATEMÁTICA}

Diferentemente do que sugere o nome, Etnomatemática não é apenas o estudo de “matemáticas das diversas etnias" (D’AMBRÓSIO, 1996), mas sim, uma forma de se adquirir conhecimentos matemáticos encontrados em nosso cotidiano e nos diversos meios que ocupamos (D’AMBRÓSIO, 2011).

Essa perspectiva em Educação Matemática é representada por D’Ambrósio (2011), conforme a relação esquemática da figura 1.

Figura 1- Esquema Etnomatemática.

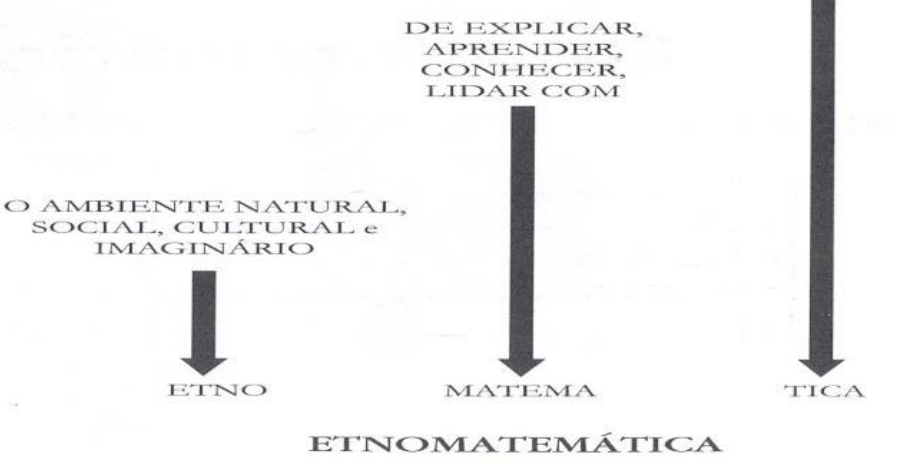

Fonte: D’Ambrósio (2011).

Segundo D’Ambrósio (2011), há diversos tipos de manifestações culturais, cada uma com suas próprias características e que definem sua individualidade. Indivíduos e povos têm, ao longo de suas vidas e ao longo da história, criado e desenvolvido técnicas de reflexão, de observação, e habilidades (artes, técnicas, techné, ticas) para explicar, entender, conhecer, aprender para saber e, daí, fazer como resposta às necessidades de sobrevivência e de transcendência (matema), em ambientes naturais, sociais e culturais (etnos) os mais diversos. (D’AMBRÓSIO, 2011). 
A Etnomatemática como atitude de ensino proporciona que seja feita uma interseção entre a prática exercida pelos sujeitos e os modelos educacionais oferecidos.

A proposta pedagógica da Etnomatemática é fazer da matemática algo vivo, lidando com situações reais no tempo [agora] e no espaço [aqui]. E, através da crítica, questionar o aqui e agora. Ao fazer isso, mergulhamos nas raízes culturais e praticamos dinâmica cultural. Estamos, efetivamente, reconhecendo na educação a importância das várias culturas e tradições na formação de uma nova civilização, transcultural e transdisciplinar (D’AMBRÓSIO, 2011, p. 46-47).

A Etnomatemática não é uma nova disciplina, assim, evita ficar sujeita aos erros da educação tradicional, isto é, não é apenas ensinar teorias e práticas prontas nos livros, esperando que o aluno seja capaz de repetir o que outros fizeram, D’Ambrósio (2011). Nesse sentido, utiliza-se muito a observação, a literatura, os diários, os jogos, o cinema, etc. Tudo isso, que faz parte do dia a dia do cidadão, e em que encontram-se importantes componentes matemáticos (D’AMBRÓSIO, 2011).

Na perspectiva da Etnomatemática, pode-se reconhecer diversas atividades do nosso cotidiano em meio às influências e expressões culturais de vários grupos sociais vinculados uns aos outros, demandando, assim, novos olhares e leituras com vistas à interação de conhecimentos e o respeito à origem do conhecimento de cada indivíduo, sem ignorar ou ainda, rejeitar as raízes do outro, para que seja permitido o fortalecimento de nossas raízes (D’AMBRÓSIO, 2011).

$\mathrm{O}$ respeito pela diversidade cultural proporciona o bem-estar individual e coletivo, o conhecimento de diferentes raízes, faz com que nossas raízes se fortaleçam.

Uma cultura é a expressão temporal de um ponto de vista singular e irredutível sobre o mundo. $\mathrm{O}$ homem não vive só do seu pensamento ou das suas capacidades cognitivas, mas também do desenvolvimento da sua sensibilidade, do seu sentido crítico, das suas faculdades criativas. Dependendo da sua felicidade e das condições que permitem a sua realização harmônica e integrada, cada cultura oferece uma "forma de vida" capaz de possibilitar esta globalidade de bem-estar humano original e histórico. As pessoas aderem às tradições que lhe proporcionam satisfação, bemestar, prazer partilhável (VERGANI, 1995, p.24).

A Etnomatemática, em sua essência, é um programa que se identifica pensamento contemporâneo e faz parte de um sistema de pensamento matemático feito com muita delicadeza e que não visa somente o desenvolvimento da cultura, mas também o entendimento do "como fazer" Matemática (D’AMBRÓSIO, 2011).

O grande motivador do programa de pesquisa que denomino Etnomatemática é procurar entender o saber/fazer matemático ao longo da história da humanidade, contextualizado em diferentes grupos de interesse, comunidades, povos e nações. Evidenciando que não se trata de propor outra epistemologia, mas sim de entender a 
aventura da espécie humana na busca de conhecimento e na adoção de comportamentos (D’AMBRÓSIO, 2011, p. 17).

Os instrumentos teóricos associados a essas técnicas e habilidades, quando devidamente contextualizados, possibilitam uma maior capacidade de enfrentamento, no que tange às situações de nosso cotidiano e de resolver problemas novos, que pelo o exposto está inserido no Programa Etnomatemática. Nessa perspectiva D’Ambrósio (2011) afirma que:

A capacidade de explicar, de aprender e compreender, de enfrentar, criticamente, situações novas, constitui a aprendizagem por excelência. Apreender não é a simples aquisição de técnicas e habilidades e nem a memorização de algumas explicações e teorias (D’AMBRÓSIO, 2011, p. 81).

D’Ambrósio (2011) afirma que "culturas estão em incessante transformação", e, portanto, estando a matemática intrínseca à cultura, consequentemente estará em constante transformação. Nesse sentido, a Etnomatemática procura partir da realidade e chegar à ação pedagógica, mediante um enfoque cognitivo com forte fundamentação cultural.

Por mais que a escola precise acelerar o processo de construção de conhecimento, que a humanidade levou milhões de anos fazendo, ela não pode acelerar a ponto de dar todo o conhecimento para a criança. $\mathrm{O}$ enfoque da Etnomatemática significa proporcionar à criança uma vivência que, obviamente, só fará sentido se ela a tiver no ambiente natural e cultural em que vive (GIANCATERINO, 2009, p. 128).

Na perspectiva de Giancaterino (2009), a Etnomatemática, em sua forma de perceber os conhecimentos naturais (culturais) dos cidadãos, prima pela "descoberta", em caráter investigativo de suas tradições, práticas e concepções matemáticas em diversos grupos sociais subordinados (quanto ao volume do capital social, cultural e econômico), a fim de que, tais conhecimentos sejam policiados de maneira pedagógica e possam ser desenvolvidos em uma prática adequada ao cotidiano de cada indivíduo e aos conhecimentos matemáticos acadêmicos, possibilitando relações entre tais conhecimentos.

A Etnomatemática vê a Matemática como um sistema cultural. E a Matemática que tem sido levada às escolas não considera essa diversidade cultural. Tem sido sempre assim a Matemática do mediterrâneo, a grega e a romana. Mas deve-se levar em conta que a cultura que floresceu em nosso planeta desenvolveu um modo de medir ou explicar o universo, bem como seu modo de quantificar (GIANCATERINO, 2009, p.131).

A partir dessa valorização dos saberes do sujeito do campo, a Educação Matemática, por meio da Etnomatemática busca um novo direcionamento para o ensino da matemática procurando valorizar 
a cultura produzida nas relações sociais, vivenciada e vinculada ao trabalho na terra e no campo, e tem como um grande desafio se consolidar como uma metodologia fortalecida e que supere a dicotomia entre rural-urbano, ao passo que que resguarda a identidade cultural dos grupos que ali constituem sua vida.

\section{ENCAMINHAMENTO METODOLÓGICO}

O lócus da pesquisa foi Casa Familiar Rural (CFR), escola comunitária localizada na Ilha de Marajó, Distrito de São Miguel, Município de Breves - PA. Atualmente a escola possui 85 alunos regularmente matriculados, divididos em três turmas: $3^{\mathrm{a}}$ e $4^{\mathrm{a}}$ etapas do ensino fundamental, e $3^{\mathrm{o}}$ ano do ensino médio.

A Escola trabalha com o ensino Profissionalizante - Ensino Médio - EJA, Integrado ao Ensino Profissional - Técnico em Floresta / Fundamentada pela resolução 467 de 20 de Dezembro de 2012, e EJA, Presencial à Educação Profissional de Nível Fundamental. Os moradores da localidade (a maioria reside nas comunidades vizinhas à Escola) vivem basicamente da agricultura familiar e do pequeno comércio local.

Vimos, na perspectiva de ensino abordada pela CFR, uma importante ferramenta educacional que desenvolve, para os moradores ribeirinhos, a expansão sociocultural e, principalmente, a valorização da agricultura familiar. Por um lado, pela possibilidade de jovens ribeirinhos, na idade escolar a partir dos 15 anos, darem continuidade em seus estudos, mesmo diante de fatores impeditivos: entre os quais foram citadas as longas distâncias entre suas residências e a escola. Também a alegação dos jovens em conciliar atividades laborais com estudo escolar, necessitando, com isso, de um sistema didático e pedagógico diferenciado das escolas localizadas em espaços urbanos.

Por outro lado, além dos aspectos mencionados, a escola CFR agrega feições atinentes às práticas sociais da comunidade local. E sua relação com o fazer matemático escolar e não escolar é diretamente vivenciada pelos sujeitos, constituindo-se, portanto, em um contexto multidimensional.

Os sujeitos participantes da pesquisa foram: os alunos de duas turmas (turma da EJA quarta etapa e a turma do $3^{\circ}$ ano do Ensino médio); o técnico em Floresta da CFR; e moradores ribeirinhos das comunidades vizinhas à escola. As atividades que envolvem as aulas de matemática na mencionada instituição de ensino são interdisciplinares, pois os professores exploram um mesmo tema/aula no decorrer da semana em alternância. 
Em uma dessas alternâncias, trabalhou-se com o tema: o meio em que vivemos, do qual se descrevem, por meio de um episódio, fatos abordados no desenvolvimento das aulas, visando interligar estes casos à ação das atividades pedagógicas desenvolvidas na CFR.

Para fins de análise, essas foram divididas em três episódios, a saber:

“O Rio Mapuá e seu sistema de comercialização”, primeiro episódio, no qual se abordou as relações estabelecidas pelo sujeito ribeirinho com as diversas estruturas presentes no sistema social, com o objetivo de compreendermos a maneira como a matemática é utilizada por esses ribeirinhos nas transações realizadas em seu cotidiano e as contribuições da Educação Matemática para a construção de uma comunidade estável a estes sujeitos.

O segundo episódio, denominado “A matemática e a cultura dos açaizais” evidencia a questão da importância no planejamento para que seja possível obter um manejo de qualidade, sendo para isso, necessária a aquisição e explanação de conhecimentos empíricos "repassados" de pai para filho.

Finalmente, no terceiro episódio, "Cubagem de madeira", foram explorados conhecimentos escolares e não escolares que eram mobilizados, ao analisar o processo de cubagem de madeira, característico da região.

Nesses episódios, foram transcritas falas dos alunos que aparecem no caderno da realidade, material denominado assim, pois é nele que o professor e a família dos alunos vão acompanhar o desenvolvimento dos alternantes. E os pais também irão deixar suas impressões, com o intuito de explicitar melhor os fatos transcorridos sobre os temas/aulas e situando-se com a pedagogia da alternância, que tem como característica "alternar tempos/lugares de aprendizado, sendo uma formação técnica em regime de internato, não podendo os alternantes abandonar por quaisquer motivos o centro de formação, onde se desenvolve um trabalho prático para a propriedade familiar e na comunidade" (RIBEIRO, 2008).

\section{APRESENTAÇÃO E ANÁLISE DOS RESULTADOS}

A matemática, como conhecimento em geral, é uma resposta às pulsões de sobrevivência e de transcendência, que sintetizam a questão existencial da espécie humana (D’AMBRÓSIO, 2011). Criam-se técnicas, teorias e práticas, para responderem às necessidades do homem, essas criações estão intimamente relacionadas com a realidade de cada sujeito.

Dessa forma, buscou-se desenvolver atividades que contribuíssem com os estudos levantados 
dentro da CFR e Comunidade Escolar, as quais denominamos: "A Matemática ribeirinha em nosso dia a dia", conforme as pesquisas realizadas e levando em consideração os Planos de Estudos dos alunos do Ensino Fundamental (EJA) e Médio da instituição de ensino, em que traçamos os debates chamados Colocação em Comum, por meio de episódios explanados da seguinte forma:

\section{Episódio I: O Rio Mapuá e seu sistema de comercialização.}

Em função das incontáveis relações estabelecidas pelo sujeito com as diversas estruturas presentes no sistema social, a Matemática surge como um fenômeno que se desenvolve na comunidade, pela comunidade e para a comunidade.

A Matemática é "uma estratégia desenvolvida pela espécie humana ao longo de sua história para explicar, para entender, para manejar e conviver com a realidade sensível, perceptível, e com o seu imaginário, naturalmente dentro de um contexto natural e cultural" (D’AMBRÓSIO, 1996, p.7).

De fato, para os ribeirinhos do Rio Mapuá que vêm há muitos anos buscando adaptar o sistema de produção rural das famílias às necessidades encontradas nos sistemas de comercialização aos quais podem ter acesso e, por meio dele, garantir o "mínimo" de qualidade possível para a criação de seus membros, a matemática apresenta-se como fator principal para a construção de uma comunidade estável (D’AMBRÓSIO, 1996).

Nesse sentido, tendo em vista a condição financeira pela qual as famílias desta localidade passam diariamente, buscou-se entender a forma de comercialização estabelecida entre as famílias ribeirinhas do Rio Mapuá (taberneiros ${ }^{4}$, regatões $^{5}$, diaristas ${ }^{6}$, etc.) que, de maneira contínua, utilizam a Etnomatemática como uma das principais articulações para suas negociações, principalmente com o sistema de comércio conhecido como escambo, troca dos seus principais produtos (açaí, farinha, melancia, abacaxi, etc.). Tais produtos são de produção natural, para pagamento de gêneros alimentícios, roupas e outros que os chamados regatões lhes oferecem no decorrer do mês.

Nessas transações, geralmente são empregadas como unidades de medida a panela (que, normalmente, equivale de três a cinco litros), o saco plástico, a lata de tinta (18 Litros), um vasilhame de plástico equivalente a cinco litros.

\footnotetext{
4 Termo utilizado pelos ribeirinhos para identificar os proprietários de pequenos comércios locais, que vendem bebidas alcoólicas e gêneros alimentícios no varejo.

5 Tipo de comerciante que trabalha por meio da compra, troca ou venda de seus produtos com os produtos dos moradores ribeirinhos, na maioria das vezes, favorecendo-se da necessidade do ribeirinho para obter um lucro muito acima do valor de mercado.

6 Trabalhador (a) que ganha só nos dias em que trabalha, ou cujo ganho é calculado por dia.
} 
As relações entre as práticas socioculturais e a matemática dialógica dos caboclos ribeirinhos evidenciam-se nesses elementos nodais, como nas unidades de medida seguintes: vendeu dez rasas de açaí; comprou um frasco ou paneiro de farinha; um litro de camarão; uma pera ou cofo de caranguejo; uma mão de milho; uma tarefa para roçar; plantou uma carreira de eucalipto; "uma linha de arroz para apanhar"; "uma sucuri com 16 palmos de pê”.

O comércio em tabernas é um elemento da cultura paraense e existe, principalmente, nas áreas mais carentes, onde a pessoa com pouca condição financeira ou sem renda fixa fica impossibilitada de comprar produtos nos supermercados da cidade. A partir dessas observações, idealizou-se uma pesquisa participativa nas comunidades ribeirinhas que, direta ou indiretamente, são alcançadas pelas atividades educacionais da instituição de ensino CFR. Assim o grupo construiu seu corpus de pesquisa, realizada de novembro a dezembro de 2013, com alunos do ensino fundamental e médio da CFR, e que resultou no trabalho apresentado no primeiro episódio:

"Vimos nessa atividade uma forma muito rica de se trabalhar a matemática em sala de aula, pois está diretamente ligada ao nosso dia a dia, já que estamos a todo o momento em contato com esses estabelecimentos comerciais, e assim, fazendo uso da matemática". (Aluno do ensino Fundamental - EJA/4 ETAPA).

Para satisfazer às necessidades dessa clientela, os taberneiros fracionam os produtos da cesta básica utilizando improvisadas unidades de medida, portanto esse comércio é conhecido por "venda ou compra a retalho". Nessa prática, para produtos líquidos, os comerciantes utilizam como medidas, "pequenos copos" que podem variar de tamanho e de material, dependendo do taberneiro. "Essas medidas são inventadas pela gente, na hora. A gente faz só se basear no valor total do produto, pensando já em quanto tem que ganhar em cima dele” (Caio - Comerciante Vila Santa Maria - Rio Mapuá).

Por outro lado, nas balanças, costumam usar objetos, como, pilhas, cadeados, pequenas barras de ferro e outros, para fazer a pesagem dos produtos. Um dado interessante da pesquisa realizada, por meio do plano de estudo, foi que a maioria desses comerciantes ribeirinhos desconhecem os múltiplos e submúltiplos das unidades de medidas, como, metro, grama e litro, pois durante a pesquisa foram solicitados a responderem algumas questões, tais como:

- Quantos gramas têm em uma quarta?

- Por que $500 \mathrm{~g}$ é igual a meio quilo?

- Quantos mililitros têm em uma garrafa de cachaça? É mais ou menos que um litro?

- Quantos copos de 200 mililitros o senhor vende com um litro de cachaça?

Contudo, diante dessas questões, eles se mostraram inseguros em suas respostas enquanto que 
outros preferiram não se pronunciar. Por outro lado, dependendo do dinheiro de que o cliente dispõe, o vendedor cria uma espécie de "unidade de medida".

A pesquisa realizada pelos alunos da turma consistia em trazer informações sobre a própria comunidade no que diz respeito às transações comerciais. Os alunos fizeram um levantamento de preços dos cinco (05) produtos mais vendidos em várias tabernas. A partir das informações coletadas, foram elaboradas atividades em sala de aula com alunos da EJA/3 $3^{a}$ ETAPA, como, no exemplo subsequente:

"Na taberna o quilo do charque custa $R \$ 14,00$ e no mercantil $R \$ 12,25$. Qual é a diferença de preço nesses dois estabelecimentos?" A resposta de um dos informantes foi: "A criança estabelece uma relação no momento da compra e venda que possibilita desenvolver competências e habilidades para calcular o preço do produto e saber se vai ou não haver troco". (A. F. G-morador da comunidade São Sebastião - Rio Mapuá).

Nessa e noutras atividades, alguns alunos "confundiram-se" na hora de "armar a operação", todavia quando perguntados sobre o resultado sem a armação do problema, ou seja, somente de cabeça, a resposta foi correta pela maioria. O que nos leva a considerar que seus "meios de estruturação", para os problemas apresentados em sala pelo professor, não foram sistematizados pela escola.

\section{Episódio II: matemática e a cultura dos açaizais.}

Uma equipe de alunos do ensino médio observou a importância do açaí tanto para a economia local, quanto para a alimentação dos Mapuaenses, tendo em vista que essa planta se espalha por enormes áreas da zona rural; que, no quintal, muitas residências há touceiras de açaí; e que a realidade de alunos e professores é diretamente afetada por essa palmeira no meio em vivem.

Neste contexto, os alunos elaboraram seu objeto de estudo e pesquisa intitulado: "Extração, beneficiamento e comercialização do açaí no município de Breves”. A partir da pesquisa também foram produzidas atividades (dentro e fora de sala), buscando desenvolver o raciocínio e a capacidade de fazer cálculos estimativos, tais como: estabelecer a média de palmeiras por touceira ou de frutinhas por "vassoura de açaí"; construir uma linha de tempo do açaí, do plantio da muda à obtenção do sumo (biometria).

Noutro momento, buscou-se fundamentar as atividades com relação a preços, quantidades e unidades de medidas empregados no trabalho com o açaí, nomeadamente o litro e a rasa. E, conforme puderam registrar, o trabalho no açaí envolve toda a família.

Na cultura ribeirinha, enquanto a mãe fica tecendo o paneiro, a peneira e outros utensílios de 
arumã, o pai sai com os filhos para o açaizal. É ele quem conhece quantas plantas frutíferas há em sua plantação e calcula quantas latas $^{7}$ ou rasas $^{8}$ irá render a safra ${ }^{9}$; calcula os gastos com o combustível do barco que irá levar a colheita à cidade (levando em consideração a potência do motor, a carga e a distância); negocia o produto e retorna com mercadorias compradas com o dinheiro da venda do açaí.

Para realizar tais estimativas o dono do açaizal deve conhecer todas as variáveis possíveis, tais como a extensão de sua plantação, a quantidade de palmeiras com frutos por touceira, o número de cachos por palmeira, a altura média das árvores, o tempo de maturação dos frutos, o auge da produção e o momento de baixa, quando o açaí começa a rarear no mercado e seu preço tende a aumentar. (A. F. G - Morador da Comunidade São Sebastião - Mapuá).

Conforme se vê, o ribeirinho é capaz de saber/fazer. Ele sabe que deve plantar 25 mudas de açaí por tarefa, com espaçamento de 4 metros.

Um dos mais importantes conceitos da Etnomatemática é o de considerar a associação existente entre a matemática e a formas culturais distintas. Assim, a Etnomatemática implica uma conceituação muito ampla do etno e da matemática. Muito mais do que simplesmente uma associação a etnias, etno se refere a grupos culturais identificáveis, como por exemplo, sociedades nacionais - tribais grupos sindicais e profissionais, crianças de certa faixa etária etc., e inclui memória cultural, códigos, símbolos, mitos e até maneiras específicas de raciocinar e inferir [...] (D 'AMBROSIO, 1990, p.17).

Acompanhando o pai, a criança vai adquirindo essa experiência e vai obtendo dele saberes matemáticos em sua própria observação e prática. Tais saberes envolvem, entre outras habilidades, cálculos precisos de tempo e espaço; a construção de modelos para as estimativas; a competência em fazer especulações e prever o melhor momento para a colheita e venda. Esses são processos bastante complexos que não passaram pela banca escolar.

\section{Episódio III: Cubagem de madeira.}

A cubagem da madeira é utilizada para avaliar a quantidade de árvores necessárias que devem ser cortadas e que serão usadas para lenha, tábuas para construção de casas, abrigos para animais, nos reflorestamentos e para negociar com os donos das serrarias.

\footnotetext{
${ }^{7}$ Termo utilizado como um sistema de medida adotado pelos ribeirinhos e que normalmente é usado para medir $15 \mathrm{~kg}$ de farinha.

${ }^{8}$ Termo utilizado como uma medida de capacidade adotada pelos ribeirinhos e que normalmente é usado para medir uma lata de açaí.

${ }^{9}$ Termo utilizado para representar a produção agrícola de um ano.
} 
A aluna "Ana", ajudada por outros colegas, relatou o que havia aprendido com seu pai e mostrou os procedimentos utilizando um pedaço de tora no trilho de uma serraria local (expondo sua colocação em comum) por meio de explanação oral e gestual:
Aluna "Ana": "Para início de trabalho, pegamos aqui na metade da tora de madeira, porque lá é mais grosso, e, aqui, mais fino [apontando para as extremidades do tronco]. Então, na metade dá mais ou menos uma média concreta. Em seguida, pego esse cordão (que pode ser um barbante qualquer, desde que seja flexível) e passo em círculo por volta da tora. Daí dobra-se o mesmo em quatro partes iguais, e depois de dobrado em quatro, vou medir ele pra ver quantos centímetros vão dar".
Vejamos: Quanto dá a medida da quarta parte do cordão se o todo é $168 \mathrm{~cm}$ ? O aluno "Breno": 42.
"Ana": "Deu $42 \mathrm{~cm}$. Agora, eu pego esse 42 e multiplico por ele mesmo, multiplico pelos 42".
"Carla Cristina": [usando a calculadora para efetuar a multiplicação] "42 por 42 dá 1764 ".
"Ana": [dirigindo-se para a colega] "Anota, pra gente não esquecer. Daí, eu vou medir o comprimento. Depois disso aí, que eu sei que tem 42, dai é que eu meço o comprimento. Deu 2 metros e 20. Agora, eu multiplico o comprimento pelo número que tinha antes, que saiu do pedacinho do barbante, que tinha dado lá, 42 vezes 42 $=1764$ ".
"Carla Cristina": "Faço este 1764 por $2 \mathrm{~m}$ e $20 \mathrm{~cm}$ ".
"Ana": "É tudo centímetro. Tem que fazer 1764 por 220!"
"Carla Cristina": "1764 vezes 220 dá... 388080”.
"Ana": "É esse número que dá."
"Diana": "388080 o quê??"
"Ana": "388080 metros cúbicos de madeira. Ou seja, aproximadamente $400 \mathrm{~cm} 3$ de madeira. Porém, segundo os madeireiros, o arredondamento correto seria $350 \mathrm{~cm} 3$ de madeira (enfatiza a aluna)".
"Diana": "Entendi... é o mesmo que fazer lado, vezes lado, vezes comprimento".
"Breno": "com este método de cubagem podemos então "criar" um padrão de corte madeireiro para que seja evitada essa grande perda de sobras e até mesmo futuros prejuizos para o fornecedor local”.

Observa-se que

Com esses conhecimentos podemos fazer uso da matemática curricular, como por exemplo, medir a altura da árvore pela sua sombra e dessa forma poder realizar uma perspectiva para exploração da mesma, tipo: Seria mais lucrativo cortar uma árvore de Andiroba ou colher e beneficiar seus frutos por safras? (ALUNO DO ENSINO MÉDIO - $\left.3^{\circ} \mathrm{ANO}\right)$.

Como o grupo estava interessado em aprender "fórmulas da matemática", depois das várias discussões sobre os métodos empregados pelos alunos, iniciaram-se as atividades com as expressões "circunferência" e "diâmetro", trabalhando em sala de aula com um conjunto de sólidos de base circular e de tamanhos diversos.

De tal modo, o processo de interpretação e decodificação dos métodos populares de cubagem 
da madeira propiciou o estudo de conteúdos ensinados nas escolas com currículos tradicionais, como comprimento da circunferência, área de um círculo, volume do cilindro e do prisma quadrangular.

Por outro lado, possibilitou aos alunos uma melhor compreensão e possível adequação de seus métodos populares, pois ao interpretarem esses processos matematicamente, puderam identificar as "sobras" de madeira que eram produzidas no "esquadrejamento" do método da aluna "Ana", exposto em classe. Concluíram que a madeira não utilizada na confecção das tábuas poderia ser aproveitada para outros fins e assim também ser contabilizada no cálculo da cubagem.

Trabalho com este tipo de cubagem desde menino. Aprendi com meu pai. Nunca usei este conhecimento para a expansão de meus negócios madeireiros e sim apenas para comprar ou vender minha produção, já perdi muita sobra de madeira que vai para o queimador. Pensando bem, "já queimei muito dinheiro" (J . B - morador da Comunidade Bom Jesus - Mapuá).

Nesse sentido, a referida pesquisa, não buscou utilizar os saberes populares apenas como uma "ponte" para os saberes científicos, houve um duplo sentido: o propósito de ensinar a matemática acadêmica, socialmente legitimada, cujo domínio os próprios grupos subordinados colocam como condição para participar da vida cultural, social e econômica de um modo menos desvantajoso. Por outro lado, as práticas populares foram valorizadas e, principalmente, "interpretadas, decodificadas, tendo em vista a apreensão de sua coerência interna e de sua estreita conexão com o mundo prático".

O propósito dessa alfabetização matemática em comunidades ribeirinhas e/ou assentamentos é, portanto, estabelecer vínculos estreitos entre a educação matemática, a cultura do grupo social (incluindo aí os métodos populares de cálculo) e sua atividade produtiva. (KNIJNIK, 1996, p. 62).

Desse modo, a cultura e a tradição do grupo são valorizadas. Não se trata, porém, da glorificação dos métodos populares, pois suas vantagens e desvantagens são discutidas e comparadas aos métodos matemáticos "escolares". Assim, o trabalhador passa a estabelecer comparações entre os diferentes conhecimentos e a ter condições de escolher aquele que lhe pareça mais adequado, ao se defrontar com situações reais (KNIJNIK, 1996).

\section{CONSIDERAÇÕES FINAIS}

A partir do trabalho realizado, nota-se que a Etnomatemática pode contribuir para tornar a matemática mais interessante aos olhos dos alunos, uma vez que ela representa um meio de promover e valorizar os saberes de sua comunidade. 
A educação não pode ater-se simplesmente em transmitir teorias e conceitos já prontos e acabados para que o aluno memorize e reproduza quando solicitado. Sua preocupação deve ser a de proporcionar instrumentos para entender e aprimorar sua condição humana. No entanto, esses instrumentos, de acordo com a Etnomatemática, só terão sentido se tiverem relação com a cultura do educando (D 'AMBRÓSIO, 1990).

É preciso acreditar que uma maior capacidade de entendimento e de compreensão é estimulada nos educandos quando a matemática é desenvolvida por meio da formulação de problemas relacionados à vivência dos alunos, situações essas que podem ser articuladas com "conhecimentos e saberes complexos, desenvolvidos a partir da observação, da experimentação e da transmissão oral dos mais velhos" (MOREIRA, 2005, p.14).

Para tal, é posto o desafio do professor em romper com o ensino matemático tradicional, cômodo, que já vem programado nos livros didáticos, muitas vezes sem ligação alguma com a realidade e distante do contexto sociocultural do aluno.

Sendo assim, um novo aspecto se apresenta para a prática do professor de Matemática em que passa a se "valer" do saber produzido pelos antigos para entender melhor os conteúdos trabalhados. Tal conhecimento torna-se uma boa estratégia em sala de aula e, por isso, o professor deve também explorar suas curiosidades e as histórias de aprendizagens das pessoas de uma dada realidade social.

Partir do conhecimento do outro, para promover uma educação mais crítica e que lhe proporcione o direito à cidadania, deve ser uma preocupação constante do educador. Na proposta da Etnomatemática, professor e aluno trocam conhecimentos, numa relação mais próxima e mais significativa para os dois.

o professor deve tratar seu aluno, recebê-lo com sua história, suas características étnicas, sua cultura e dar a ele elementos da ciência dita institucional, para que o complemente como um elemento novo dentro da sociedade. Sem destruir em hipótese alguma toda sua cultura e mais importante ainda: estes elementos novos que lhe serão ensinados devem realçar e valorizar os antigos. (FERREIRA, 2004, p. 189).

A matemática desenvolvida pelos diferentes grupos sociais pode não ser a mesma da acadêmica, mas demonstra ser, na maioria das vezes, adequada às situações e necessidades de sobrevivência desses mesmos grupos (FERREIRA, 2004).

Diante dos pressupostos do Programa Etnomatemática, há a possibilidade de salientar que nossos alunos de classes menos privilegiadas não são menos inteligentes que seus colegas de maior poder aquisitivo e melhores condições sociais, simplesmente sua visão de mundo é diferente, já que seu cotidiano e suas prioridades são outras. 
Um pressuposto fundamental para a Etnomatemática é que a diversidade cultural contribui para tornar a humanidade mais rica. Por isso, é atribuído ao professor o papel de explicitar ao aluno a existência de outras culturas, além da sua, tendo em sua subjacência a preocupação com a promoção da solidariedade entre os diferentes. Nesse sentido, a Etnomatemática torna-se um grande instrumento de valorização do saber-fazer matemático dos vários grupos sociais e, seu papel não pode ser desprezado pelo educador matemático comprometido em melhorar a autoestima de seus alunos, motivando-os de tal maneira que possam sonhar e buscar um futuro mais digno e mais justo.

No entanto, vale salientar que o mencionado programa exige um novo olhar para os diversos componentes da prática docente, como: a concepção de matemática, ensino, aprendizagem, avaliação. Há de se ressaltar que a Etnomatemática é uma opção educativa bastante recente, em vias de expansão, pois basicamente foi assumida por professores/pesquisadores, muito mais como objeto de pesquisa do que uma efetiva prática docente em sala de aula.

Contudo, é, entre as diversas tendências atuais em Educação Matemática, a que mais se aproxima das aspirações daqueles que almejam: a formação de alunos reflexivos; a articulação entre os diversos saberes (cotidianos e científicos) e a contribuição da matemática para a conquista da cidadania e da paz entre as pessoas e as nações.

\section{REFERÊNCIAS}

D’AMBROSIO, Ubiratan. Etnomatemática, justiça social e sustentabilidade. Estudos avançados, São Paulo, v. 32, n. 94, p. 189-204, Dec. 2018.

D’AMBROSIO, Ubiratan. Etnomatemática: Arte ou técnica de explicar e conhecer. São Paulo: Ática, 1990.

, Educação matemática: Da teoria à prática. Campinas, SP: Papirus, 1996.

Etnomatemática: Elo entre as tradições e a modernidade. 4. Ed. - Belo Horizonte: Autêntica Editora, 2011.

FERREIRA, Eduardo Sebastiani. Etnomatemática: um pouco de sua história. In: Monteiro, Alexandrina et al. Etnomatemática na sala de aula. Natal: UFRN, Coleção Introdução à Etnomatemática, v.II, 2004.

GIANCATERINO, Roberto. Matemática sem rituais. Rio de Janeiro: Wak Ed., 2009. 188p.

KNIJNIK, G. (2010). A matemática da cubação da terra. In: Scientific American Brasil, aula aberta 3, pg. 56-60. Moderna, 2010. 
KNIJNIK, Gelsa. A matemática da cubação da terra. Revista Scientific American Brasil Etnomatemática, nº 11. Ed. Especial. São Paulo: Duetto Editorial, 2005, p. 86-89

KNIJNIK, Gelsa; DUARTE, Claudia Glavam. Entrelaçamentos e dispersões de enunciados no discurso da educação matemática escolar: um estudo sobre a importância de trazer a" realidade" do aluno para as aulas de matemática. Boletim de Educação Matemática, v. 23, n. 37, p. 863-886, 2010 .

RIBEIRO, Marlene. Pedagogia da alternância na educação rural/do campo: projetos em disputa. Educação e Pesquisa, v. 34, n. 1, p. 27-45, 2008.

MOREIRA, Luíza Castro. Na floresta dez, na escola zero: a construção do conhecimento matemático na zona ribeirinha do município de Melgaço, PA. 2005. 53 f. Monografia Graduação em formação de professores da Universidade Estadual do Pará, Belém, 2005.

SOUZA, J. C. BICHO, J. S.; NASCIMENTO, L. J. O. Etnomatemática e Pedagogia da Alternância: um diálogo possível para a valorização dos saberes da tradição. In: XIII Conferência Interamericana de Educação Matemática, 2011. Recife. Anais... XRecife: III CIAEM, 2011.

VERGANI, T. Excrementos do Sol: a propósito de diversidades culturais. Lisboa: Pandora, 1995. 